\title{
Religión, medicina popular y curanderos en la provincia de Buenos Aires (Argentina, 1880-1941)
}

\author{
[Religion, Folk Medicine and Folk Healers in Buenos Aires Province \\ (Argentina, 1880-1941)]
}

Astrid Dahhur

(Universidad Católica Argentina)

astridahhur@gmail.com

\begin{abstract}
Resumen:
La medicina popular ha empleado diversas prácticas -la herboristería y la magia han sido algunas de ellas- para curar diferentes males tales como esguinces o hasta cuadros bacterianos o virales. Desde la medicina académica se buscó desacreditarla en un intento por monopolizar el campo. Uno de los motivos por los cuales su éxito fue relativo fue el componente cultural de la medicina popular, representado en algunos aspectos religiosos de las curas empleadas por sus agentes: los curanderos. En este artículo analizaremos la impronta de la religión en algunos casos de medicina popular a través de fuentes judiciales de la provincia de Buenos Aires, Argentina, en un período de sesenta años.
\end{abstract}

Palabras clave:

Medicina Popular; Fuentes Judiciales; Religión; Argentina

\begin{abstract}
:
The folk medicine has used various practices in order to cure, such as herbal medicine and magic. Academic medicine searched to discredit folk medicine so it could monopolize the field. One of the causes of the failure of the academic medicine is the cultural component, we refer to the religious aspects used by the folk healers during their healing practice. In this paper we analyze how important was the religion in some cases of folk medicine through judicial records in Buenos Aires province during sixty years.
\end{abstract}

\section{Key words:}

Folk Medicine; Judicial Record; Religion; Argentina

Recibido: 23/05/2019

Evaluación: 01/08/2019

Aceptado: 16/03/2020

Anuario de la Escuela de Historia Virtual - Año 11 - N 17 - 2020: pp. 36-56.

ISSN: 1853-7049

http://revistas.unc.edu.ar/index.php/anuariohistoria 


\section{Religión, medicina popular y curanderos en la provincia de Buenos Aires (Argentina, 1880-1941)}

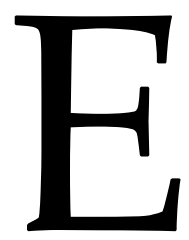

n los últimos años, desde la historia de la salud y la enfermedad en la Argentina, se ha prestado atención a la medicina popular (Rivero, Carbonetti y Rodríguez, 2017; Rivero y Vanadía, 2018; Rivero y Carbonetti, 2019; Allevi, Carbonetti y Sedrán, 2018) en relación a sus implicancias en el desarrollo de los sistemas sanitarios, la salud de la población y las tensiones que existían entre los académicos y los empíricos. Esto es algo que ya a nivel latinoamericano ocurría para Brasil (Weber, 1999; De Almeida, 2018), Colombia (Sowell, 2002; Márquez-Estrada, 2018) y Costa Rica (Palmer, 2003). Hasta hace unos años, este fenómeno era solamente mencionado como la antesala del proceso de medicalización. La medicina popular, según se ha reconstruido, fue el enemigo elegido -entre otras estrategias- por las corporaciones médicas desde mediados del siglo XIX para hacerse del monopolio, de los saberes de la salud y la enfermedad de la población.

La persecución y el descrédito hacia las prácticas médicas no institucionalizadas se prolongaron en el tiempo hasta avanzado el siglo XX en la Argentina. Uno de los argumentos más empleados fue la equiparación de sus conocimientos y rituales a la superstición, sumado al componente religioso que en la visión de la medicina académica les restaba cientificidad. Independientemente de las apreciaciones sobre ciertas prácticas de la medicina popular, especialmente las ligadas a enfermedades como el ojeo y la culebrilla, los aspectos de la religiosidad de la curación eran necesarios, casi imprescindibles para patologías relacionadas con lo divino o la maldad, el mal de ojo, el susto, el daño, entre otras. La religiosidad, como señalamos, fue un componente esencial para comprender algunos de los casos de curanderismo que analizamos. Lejos de señalar que fueron un ejemplo de sugestión y superstición, entendemos que esta forma de curación fue una expresión de la hibridación cultural presente en la medicina popular. Una manifestación que no fue aislada, sino que se replicó en el territorio argentino a lo largo de los años (Bianchetti, 1982; Farberman, 2005; 2010; Arteaga, 2008).

Nuestro cuestionamiento respecto a la relevancia de la religión en las prácticas curativas nos llevó a realizar una clasificación de las distintas formas de curar. En nuestra investigación, la cual forma parte de nuestra tesis de doctorado, hemos clasificado en tres categorías las prácticas médicas: empíricas, religiosas e híbridas. Las primeras eran las ligadas al empleo de plantas, minerales y partes de animales que, a través de los años, se señaló que poseían propiedades curativas. Las religiosas eran aquellas que se remitían al empleo de fórmulas, normalmente del dogma cristiano, para curar enfermedades, como, por ejemplo, el ojeo. Y, por último, las híbridas eran una conjunción de las dos 
anteriores. Es decir que, en ciertos casos, la religión estaba ligada a las prácticas de la medicina popular.

En este artículo nos proponemos destacar la relevancia de las prácticas religiosas en la realización de curaciones, dado que su presencia estaba vinculada con nociones culturales transmitidas de generación en generación con orígenes en la etapa colonial (Farbeman, 2010). Entendemos que, más allá de que ciertas personas en su desesperación pudieran apelar a fórmulas religiosas para su curación, existieron también componentes de carácter cultural que hicieron que ciertos enfermos emplearan estos conocimientos para poder realizar una curación. Estas constataciones, también, nos permiten contribuir a un mayor conocimiento sobre las limitaciones que tuvo el proceso de medicalización en la provincia de Buenos Aires en el período delimitado.

Para demostrar esto empleamos documentación de carácter judicial. Este tipo de fuentes tiene la particularidad de permitirnos, con el debido cuidado metodológico, acceder a comportamientos, pensamientos y discursos de los sectores populares, como así también a las imágenes construidas por los agentes del estado acerca de sí mismos y de sus acciones. Finalmente, el empleo de esta documentación nos permite reconstruir el ambiente socio-cultural de la llamada medicina popular y comprender de manera más acabada el proceso de medicalización.

En las siguientes páginas, en principio, realizamos un breve repaso de las condiciones socioeconómicas de la provincia de Buenos Aires. A continuación, nos detenemos en señalar las diferentes posturas sobre los conceptos de religión y religiosidad. Posteriormente, analizamos expedientes judiciales provenientes del Departamento Judicial del Sud de la Provincia de Buenos Aires (jurisdicción que abarcaba el sudoeste de la provincia para cuestiones de índole judicial), rotulados bajo la carátula "ejercicio ilegal de la medicina" desde fines del siglo XIX hasta mediados del XX. El término utilizado para rotular las causas no es menor, puesto que señala la criminalización estatal de las prácticas curativas populares y la puesta en valor de las instituciones del saber médico diplomado. Sin embargo, esto no garantizó que todos los acusados fuesen hallados culpables o que los jueces no los protegiesen.

\section{El escenario: la provincia de Buenos Aires}

Todas las localidades que investigamos, que alojaron a los curanderos durante sus viajes, tenían como característica primordial la importancia de la explotación agrícola ganadera. El período abarcado en este trabajo es de una extensión temporal amplia durante la que convergieron diferentes coyunturas políticas, económicas y sociales. Una de sus peculiaridades fue que tuvo una frontera productiva en expansión hasta las primeras décadas del siglo XX y que constituyó una de las mayores receptoras de inmigrantes desde 1830 debido a las oportunidades laborales generadas por su inserción productiva en el mercado mundial. Así, en la década de 1870, Buenos Aires receptó 30.000 personas (Bjerg, 2004, p. 22) que llegaban en busca de trabajo, ya fuese desde otras 
provincias como de ultramar, gracias a las políticas de estímulo de la inmigración del Estado Nacional. Esta circulación de personas propició la llegada de saberes curativos desde diferentes regiones, al igual que de creencias religiosas ligadas a los mismos. El propio Estado argentino fue promotor de diversas medidas para favorecer la inmigración ultramarina. Aunque existieron variaciones, productos de las coyunturas locales e internacionales, la promoción de pasajes, el hotel de inmigrantes y las cadenas migratorias generadas por los mismos extranjeros hicieron de la Argentina un país receptor de inmigración hasta la década del treinta. Si bien la mayoría de estas personas se concentraron en los centros urbanos, las áreas rurales fueron destinatarias de diferentes grupos de extranjeros. Los danenses (Bjerg, 2004), españoles (Da Orden, 2005) o vascos (Irianni, 2000) e italianos son algunos casos de la inmigración en zonas rurales de la provincia de Buenos Aires.

Hacia fines del siglo XIX la expansión agrícola cambió la forma de colonización de la pampa argentina, particularmente en nuestra área de estudio. La extensión de la frontera agrícola propició una modificación en los cultivos desde la década de 1860. Esta fue una razón determinante para que a fines del siglo XIX el impulso inmigratorio se asentara en Buenos Aires y Córdoba. En 1850 y hasta 1860 la expansión lanar del norte de la provincia de Buenos Aires favoreció la llegada de los inmigrantes de origen irlandés. Esta expansión derivó, sumada a los conflictos políticos que atravesaba la Provincia, en un desarrollo desigual de la misma (Míguez, 2009).

La Federalización de Buenos Aires en 1880 señaló una nueva configuración espacial al igual que los cambios introducidos en materia económica y social. Los diferentes patrones de asentamiento en la provincia fueron modificados gracias a la llegada lenta, pero efectiva, del ferrocarril al sur de la provincia, tal como lo atestiguan los casos de Castelli, General Guido, Dorrego, Balcarce y General Pueyrredón (Levene, 1940). En la frontera norte encontramos la zona de ocupación más antigua de la provincia. Allí, se conjugaban antiguas estancias explotadas por sus dueños y pequeñas parcelas trabajadas por arrendatarios y aparceros y algunos inmigrantes que se habían hecho de las propiedades. Al sur de Buenos Aires y al norte del río Salado se encontraba el último territorio colonial cercano a la ciudad (Quilmes y la actual ciudad de Chascomús), al que beneficiaría rápidamente el sistema ferroviario. Sus tierras estaban destinadas al ganado, primero ovino y luego bovino, entre 1880 y 1890. En esta zona sería donde se instalaría la futura capital provincial. El resto de la provincia era la frontera sur que hasta la década de 1870 fue víctima de los malones. La llamada ocupación cristiana hasta esa fecha se dio de manera lenta y constante y solo Bahía Blanca era controlada por el Estado, dada la ventaja de su puerto.

Con la crisis de 1890, la bonanza agrícola no se vio resentida, pero no sucedería lo mismo con la economía urbana. Míguez (2013, p. 23) rescata esto y destaca, a través de los datos censales, cómo en 1895 la población urbana disminuyó en contraste con la rural. Hacia 1900 llegó el gran auge económico gracias a las cosechas de trigo, maíz y lino sumado a la posterior exportación de carnes congeladas y, más tarde, refrigeradas. 
Además, el crédito agrario se restableció, lo que favoreció la inversión de parte de los empresarios terratenientes.

Los cambios en los modelos de producción, el paso del ganado lanar al vacuno o el incremento de los cultivos cerealeros (localidad de Dolores) atrajeron a la población. Con la llegada del ferrocarril se activó otro tipo de economía como el turismo (partido de General Pueyrredón, particularmente la ciudad de Mar del Plata). Los censos poblacionales nacionales de 1869, 1895 y 1914 junto con el provincial de 1881 permiten reconstruir el peso de las diferentes actividades a lo largo de los años y, sumados con otras fuentes, explorar el panorama social y cultural que facilitó la presencia de curanderos.

El trabajo de Adrián Carbonetti (2009) es útil para entender la presencia y ausencia de curanderos en la Argentina mediante el empleo de documentación censal. Sin embargo, al basarse solamente en datos cuantitativos no puede aseverarse que la totalidad de los curanderos fueran contabilizados, varios probablemente no se definieron como tales para evitar represalias. Esto es entendible, puesto que desde el Estado y la corporación médica se intentó reducir la cantidad de curanderos mediante su control y sanción, tal como lo atestiguan las causas por ejercicio ilegal de la medicina.

En síntesis, la llegada de inmigrantes y la expansión agrícola hicieron que la población aumentase más rápido que los recursos humanos (médicos, parteras diplomadas, enfermeras) y materiales (hospitales). El Estado nacional y el provincial, a pesar de sus esfuerzos, tuvieron problemas en la asignación de dinero, infraestructura y médicos (Biernat, 2015) e incluso de jurisdicción, al superponerse atribuciones y obligaciones en el control sanitario de la población. La escasez de médicos en la campaña en este período estaba relacionada (González Leandri, 1999) con las escasas posibilidades existentes para vivir de la profesión por dos motivos: la situación económica de los enfermos y las creencias y prácticas ligadas a su propio bagaje cultural (Dahhur, 2015). Para comprender esto, abordaremos ahora las nociones ligadas a la religiosidad y la curación de enfermedades en la campaña bonaerense.

\section{La religión y la religiosidad en el centro}

El ejercicio ilegal de la medicina o curanderismo -como en ocasiones figuraban en las carátulas de los expedientes en los siglos previos (Farberman, 2005) y también durante el mismo siglo XIX- guardaba en el imaginario colectivo una fuerte relación con los términos brujería y superstición, nociones que en la segunda mitad del siglo XX desaparecieron de los argumentos acusatorios. Esta fue una modificación sustancial en la cosmogonía de la sociedad que indica el avance de una nueva visión del mundo, el de la ciencia y la razón por sobre la religión sumado a un proceso de secularización (Di Stefano, 2011, p. 4).

A principios del siglo XX y en las mismas ciudades aún existía la creencia en "supersticiones", como a veces denominaban a las prácticas de la medicina popular: 
"Aunque en los centros civilizados no se cree ya en augures y oráculos, subsiste en las gentes cierto fondo supersticioso que las hace entregarse a otros simuladores del mismo género: las adivinas y los curanderos" (Ingenieros, [1903], 1985, p. 75). Di Liscia (2002, p. 205) ha trabajado esta cuestión, especialmente la noción de sugestión, a través de los casos de Pancho Sierra y la Madre María. Estos dos personajes tenían en común el empleo de la religiosidad en la curación de los enfermos. Sin embargo, esta autora se centra en los procesos acusatorios y toma a los dos curanderos como sugestionadores. Nosotros, por el contrario, lejos de esta postura, hallamos en la religiosidad uno de los componentes esenciales del curanderismo, particularmente en el tratamiento de ciertas enfermedades con un fuerte componente psíquico.

Algunos trabajos han señalado que la religión perdió su lugar producto del proceso de secularización de la sociedad que tuvo sus inicios en la Argentina del último cuarto del siglo XIX (Di Stefano, 2011), esto dio por resultado el "divorcio" entre la Iglesia y el Estado. Una de sus consecuencias fue el ascenso de la ciencia y la educación laica en la población argentina. Esta noción, empero, ha sido cuestionada por Fortunato Mallimacci (2008, pp. 85-86), quien no percibe en el surgimiento de la modernidad una desaparición de la religión en la sociedad argentina. En sintonía con esto último es que encontramos en los argumentos acusatorios por parte de médicos, comisarios y fiscales una asimilación entre el concepto jurídico de ejercicio ilegal de la medicina con los de curanderismo y superstición.

Además del discurso cientificista del siglo XIX, que se profundizó en el XX, la visión de la medicina popular como un resabio de las prácticas paganas y/o supersticiosas sentó sus fundamentos en la presencia de aspectos religiosos y, más bien, de religiosidad popular. Este concepto ha suscitado debates en los últimos años respecto a la utilización o no de la religiosidad popular en las investigaciones (Fogelman, 2010; Martin, 2007). Particularmente se lo ve como un término estigmatizante con el que se tilda todo aquello que escapa a la órbita de la religión institucionalizada. La religión puede ser entendida como parte de una institución, con un dogma que fija, marca la ritualidad y las creencias de sus seguidores. La religiosidad, por otro lado, sería la manifestación de fe que escapa a los designios de las instituciones religiosas. Julio Caro Baroja, al hacer referencia a esas diferencias, ha señalado que: "religiosidad, entendiendo que esta palabra se refiere, más que a 'la práctica y esmero en cumplir las obligaciones religiosas', a la facultad de practicar una religión, dentro de las limitaciones individuales y sociales que le son impuestas a todo hombre al nacer" (Caro Baroja, 1995, p. 21).

Paralelamente Daniel Santamaría (1991) define a la religiosidad no solo como parte de lo litúrgico, lo ritual o lo cultural, sino que la incluye en una amplia gama de comportamientos individuales y colectivos que definen el proceso global de simbolización. Igualmente, siguiendo la línea de Eloísa Martín, debemos tener en cuenta el concepto temporal y analizar cada caso acorde al proceso histórico en el que se desarrolló concibiendo a la religiosidad como un concepto dinámico y no estático. 
En esta clave, un elemento central en la conexión entre la medicina popular y la religiosidad, y su consecuente adjetivación como superstición, es la ritualidad de las acciones. Acerca de este último concepto resaltamos la diferencia que posee respecto a la doctrina de cualquier religión. La religión se basa en un cuerpo de dogmas o verdades establecidas reguladas por una institución, en nuestro caso la Iglesia Católica, el cual es rígido, por lo que no puede ser sujeto a interpretación ni modificarse con facilidad. Inclusive los ritos están fijados para ser desarrollados de una cierta manera. Nos referimos a religiosidad en el sentido de adaptación, redefinición y/o suma de ciertas prácticas o creencias al corpus de la religión, en la cual no debe perderse de vista la cuestión del sincretismo cultural. Los santos populares no reconocidos por la Iglesia, la mezcla de creencias religiosas con ciertos actos como los de curación, el ojeo, el empacho, la culebrilla, la curación del hipo mediante el rezo de tres Ave María mientras se bebe un vaso de agua, son algunos ejemplos. Los curanderos hacen uso de la religiosidad popular para la cura mediante la fe. En estas enfermedades lo que apreciamos específicamente es una concepción mágica de la enfermedad, algo maligno me enfermó, por lo tanto, su antítesis, Dios, es el único que puede curarme o una fuerza superior (Viotti, 2014, p. 155).

La religiosidad en varios casos tenía una relevancia tal que el mismo José María Ramos Mejía, médico y psiquiatra del siglo XIX, apuntaba como un componente imprescindible a la ritualidad en la acción de lo que él denominaba médico gitano: "Su solemnidad, cuando necesita simularla como revestimiento de la sabiduría, es emocionante; siempre toma aptitudes de misa y no levanta los ojos al cielo ni los cierra con la unción del 'sacrificante'" (Ramos Mejía, 1904, p. 248). Y concluye la idea llamándolo irónicamente "sacerdote del sagrado fuego de la vida" (Ramos Mejía, 1904, p. 249). El empleo de la religiosidad como mecanismo de curación fue duramente criticado por los contemporáneos de los casos analizados. Desde la psiquiatría a fines del XIX y principios del XX se apuntaba al curanderismo como uno de los factores determinantes en el recrudecimiento de las enfermedades mentales (Mailhe, 2017, p. 2). Si bien la fe en el curandero no era determinante, la necesidad de creer favorecía la presencia de estos personajes, sumado a los cambios producidos en la sociedad por la expansión agrícola, las modificaciones en el sistema productivo, los adelantos tecnológicos, la inmigración ultramarina, entre otros. Ratier (1972, p. 10), años atrás, ha señalado que en la "medicina curanderil" el peso de las nociones religiosas es un aspecto característico, lo que guarda una estrecha relación entre las pócimas que se preparaban y las oraciones recitadas para sanar. El antropólogo separa en sus trabajos a la medicina popular (aquella no institucionalizada) del curanderismo, que posee un componente religioso. Debido a ello, se utiliza el término sanar, que implica una afección más ligada al alma que a lo fisiológico.

En este sentido, Bubello (2007, p. 78), parafraseando a Daniel Granada, hace hincapié en el término sanación en lugar de curación, al considerar que sus mecanismos de diagnóstico consistían en los análisis de vasos de agua y la sanación del enfermo. Esto 
implicaba que los orígenes y mecanismos de reconocimiento de las enfermedades que sanaban escapaban al orden de lo biológico y guardaban relación con cuestiones de índole energética, es decir, lo que normalmente se llamaban males. A esto se sumaban los conocimientos de hierbas para la curación de diferentes patologías, lo cual generaba un sistema híbrido de prácticas basado en la empiría, conocimientos de prácticas adquiridos mediante la experiencia propia o de terceros, y la religiosidad con oraciones y rituales que aseguraban el éxito del tratamiento.

El ritual es inherente al proceso de sanación. Teniendo esto en cuenta se comprende la descripción de la metodología terapéutica que realiza Granada sobre los manosantas (un tipo de curandero), como una persona que curaba sin esperar una remuneración, pues era su deber emplear para el bien los poderes que Dios le confería. Aplicaba medicamentos, pero lo que le distinguía y caracterizaba era el uso de la señal de la cruz y de velas encendidas delante de un crucifijo o de la Virgen. No interrogaba sobre la enfermedad del doliente, le bastaba conocer el lugar del dolor para santiguar la parte enferma. La práctica curativa consistía básicamente en ubicar el crucifijo o la imagen en una mesa. Encendía tres velas adelante y rezaba con las manos cruzadas. El paciente también rezaba con los ojos fijos en el crucifijo o la imagen. Luego, el manosanta hacía con la mano o el dedo pulgar la señal de la cruz en el lugar en que entendía se hallaba localizada la dolencia. En resumen, la ritualidad y los componentes religiosos no fueron inhabituales en las prácticas de los llamados curanderos.

\section{Curanderos y religión a través de los viajeros}

Básicamente el uso de la religiosidad por parte de los curanderos consistía en el recitado de oraciones, el empleo de algunos pases o la imposición de manos sobre personas $\mathrm{u}$ objetos. Utilizar el carisma y sus supuestos dones extraordinarios para poder realizar acciones imposibles fueron algunas de las atribuciones dadas a estos personajes. Para quienes acudían a ellos, estos podían ser capaces de realizar acciones y curas extraordinarias debido a sus conocimientos y poderes especiales. La idea de que estaban en un pedestal por encima del resto de las personas es significativa. Por ejemplo, el Tata Dios de Tandil en 1871. A este personaje se le atribuían curaciones milagrosas que lo hicieron merecedor del título "Médico Dios" y le posibilitaron ejercer una influencia que -para los actores de la época derivó en una matanza- con un discurso fuertemente mesiánico (Nario, 1976; Santos, 2008).

Ya anteriormente el etnógrafo Daniel Granada, de fines del siglo XIX, explicaba el peso de la religión en el curanderismo:

El curandero por mucha conciencia, o temor de Dios que tenga, tendrá que decirlo forzosamente en la mayor parte de las curaciones. Lo que le salva, que para suplir su deficiencia, antepone a la propinación de la pócima, junto con su buena intención, la frase consagrada: este remedio le curará, con la ayuda de Dios, como Dios sea servido, si Dios 
quiere, etc. (...) pero solamente usa aquellas (hierbas) cuya bondad tiene acreditada la experiencia, y que conoce por tradición (Granada, [1896] 1947, p. 287).

Algunos viajeros hicieron mención en sus memorias y relatos respecto de las costumbres de la campaña sobre la existencia de curanderos y sanadores populares. Al describir las prácticas de los sanadores indígenas de los pampas, por ejemplo, mencionaban que "los 'machis' o curanderos, prácticos en la preparación de hierbas medicinales, pero todavía emplean como remedios algunos procedimientos bárbaros. (...) si algún enfermo sufre de alguna dolencia interna incurable, le abren el costado cortándoles un fragmento del hígado y se lo hacen comer" (Macc Cann, [1847], 1939 p. 103).

Como podemos ver, a ojos de nuestro observador, los machis y los curanderos eran lo mismo. Los machis eran los médicos de las sociedades originarias, quienes se encargaban de la salud tanto como de las cuestiones religiosas, eran autoridades respetadas, $\mathrm{y}$, por lo general, mujeres. Hoy se las denominaría brujas o chamanes.

En este sentido, Henri Armaignac, médico residente en el actual partido de Necochea (Santa Cruz del Moro), tuvo un buen número de pacientes tras su arribo, en 1874. Según él, eran "las brujas" quienes desempeñaban el papel de médicas, curaban fiebres, sanaban heridas, acomodaban huesos y utilizaban para su labor desde hierbas de la región hasta grasas de leopardos, tatú y avestruces, entre otros. El llamar brujas a esas mujeres puede encerrar dos cuestiones: la primera, una denostación de su accionar y, por ende, la utilización de un apelativo que podía ser ofensivo. En segundo lugar, el empleo de este vocablo puede denotar el esfuerzo por explicar un fenómeno desconocido para su propia cosmogonía o ambas cosas. Por otro lado, el mismo Armaignac se contradecía al decir que las brujas curaban fiebres y empleaban hierbas. Al señalar esto, les atribuía un saber específico, un conocimiento, reforzando así la hipótesis de una convivencia en la campaña de médicos titulados y curanderos, siendo complementarios los unos de los otros y atendiendo a diferentes necesidades de la población. Además, mencionaba otras formas de curar mediante "pases mágicos, drogas simples, pollos vivos o sacrificados" (Armaignac, 1976, p. 94).

Hallamos en este tipo de prácticas una interdependencia entre el agua y la religiosidad. La lógica de la taumaturgia combinada con la palabra y el agua en personas cuyos trastornos probablemente eran de origen psicosomáticos favorecía la idea del milagro y de la curación inexplicable. Este aspecto asociado a prácticas médicas con una cierta ritualidad en el siglo XIX y XX no es tan excepcional como podría pensarse apriorísticamente. Otros casos en provincia como Córdoba (Rivero, Carbonetti, Rodríguez, 2017), Jujuy (Fleitas, 2007) y en la ciudad de Buenos Aires (Vallejo, 2018) permiten pensar en una relación intrínseca, como así también lo veremos en este artículo. Un tipo de documentación diferente que permite analizar esta relación es la judicial. A continuación, presentamos una serie de casos judiciales sobre ejercicio ilegal de la medicina que tienen en común el empleo de la religiosidad para curar ciertos males. 


\section{Curanderos y religiosidad en la documentación judicial}

Un ejemplo del empleo de la religiosidad ocurrió en Coronel Pringles en 1895. Sixto Jofre, conocido como el "médico del agua fría", fue un curandero de Coronel Pringles que rechazaba las acusaciones sobre recetar remedios de botica y resaltaba que solo usaba agua $\mathrm{y}$, en ocasiones, infusiones con cáscara de naranja y eucaliptus. Cuando le preguntaron sobre la muerte de dos de sus supuestos pacientes dijo no saber nada y acerca de lo que administraba reafirmó: “Que lo que administra á la cáscara de naranja y no en sí remedio de botica y sí alguna cosa les dá [sic] no es como dejó dicho remedio de botica". ${ }^{1}$ Además, al cuestionárselo sobre el delito de ejercicio ilegal de la medicina afirmó: “que él no va a asistir a nadie sin que lo llamen y que lo hace en nombre de Dios como lo venia haciendo en todas partes sin que nadie lo haya prohibido él no va como médico". ${ }^{2}$ Varias cosas se pueden rescatar de este testimonio. Primero, la clara negación de ser médico. En relación a esto, la idea de que solo prestaba asistencia a aquellos que lo solicitaban pues su profesión era la "hacer bien a todos". ${ }^{3}$ Esta expresión, conjugada con la creencia de que el agua suministrada por intercesión de Dios podía curar, intentaba demostrar un alma samaritana e incapaz de obrar en contra de sus hermanos. Algo similar a lo que afirmaba Pancho Sierra, quien aseveraba curar mediante el agua y la fe. Este argentino de 55 años creía aparentemente tener una misión divina. Y por ello mismo no se autoproclamaba médico, sino que curaba por intermedio de Dios.

Las nociones religiosas en las prácticas de la medicina popular son amplias: curar mediante agua y también aceite se vincula con rituales propios del cristianismo, dos elementos empleados en los sacramentos de esta fe. Por otro lado, la idea de hacer el bien y de poner al servicio de los demás su obrar implicaba implícitamente una negación a cualquier tipo de recompensa pecuniaria. Esto último jugaría un rol fundamental, pues uno de los agravantes judiciales era el cobro por los servicios prestados. A su vez, negaba llamarse médico y atendía solamente a quienes se lo solicitaban.

Las infusiones y procedimientos prescriptos lejos estaban de ser una práctica medicinal inusual en la zona, pues, en el siglo XIX los tratamientos con agua eran célebres en la provincia de Buenos Aires (Dahhur, 2019). La pregunta sería: ¿podía considerarse ejercicio ilegal de la medicina este tipo de infusiones y prácticas comunes en la campaña bonaerense? Sixto Cufré o Jofre, por ejemplo, tenía como método característico el uso del agua para la curación de diversos males: “el mencionado Cufré o Jofre suministra generalmente agua fría, unto sin sal, paños de agua fría, infusión de eucaliptus y de cascara de naranja, grasa de potro y baños generales". ${ }^{4}$

\footnotetext{
1 Archivo Histórico Departamento Judicial del Sud de la Provincia de Buenos Aires, Justicia Criminal (en adelante AHDJSPBS/JC). Exp. 172/13/1895 f. 3.

2 AHDJSPBS/JC. Exp. 172/12/1895 fs. 2-3.

${ }^{3}$ AHDJSPBS/JC. Exp. 172/12/1895 f. 3.

${ }^{4}$ AHDJSPBS/JC. Exp. 172/12/1895 f. 1.
}

Anuario de la Escuela de Historia Virtual - Año 11 - Nº 17 - 2020: pp. 36-56. ISSN: 1853-7049 
La declaración de Cufré o Jofre era clara al respecto. Él no era médico, ni siquiera se proclamaba como tal, sino que era un alma caritativa que ayudaba a quien lo necesitase: "no los asiste como médico sino que les da agua en el nombre de Dios que es lo que hace con todos los que lo ocupan pues son varios y que no les cobra nada". ${ }^{5}$ Esta práctica no debe considerarse inhabitual pues el agua era un elemento purificador, principalmente si se busca una relación con el bautismo. A esto debe sumársele la creencia de que el agua magnetizada o energizada era capaz de curar enfermedades como el reuma. Esta fue a fines del XIX una terapia extendida en diversos sectores poblacionales (Conforte y Vallejo, 2016).

Otro caso tuvo lugar en 1901 en la localidad de Coronel Suárez. El expediente con fecha del 14 de diciembre se iniciaba con una carta en la cual se señalaba que Francisco Díaz había acudido al médico del poblado para pedir un certificado de defunción para su hijo, Vicente, quien había fallecido luego de un mes de enfermedad. Hasta allí no se presentaba anormalidad alguna, salvo que este había sido asistido por "el curandero Don Manuel Games", quien no pudo determinar la causa de la defunción. ${ }^{6}$ De acuerdo a la misiva, el fallecido de cuatro meses de vida fue atendido por "Manuel Games quien se titula médico del agua fría"7 por lo que, para averiguar los motivos que llevaron a su muerte, se pidió una autopsia.

Inmediatamente en el expediente encontramos la declaración del padre del niño, un jornalero argentino de 39 años, quien aseveró haber pedido los servicios del Dr. Peña, para que reconociera el cadáver de su hijo. Cuando le preguntaron sobre la causa de la muerte afirmó que no sabía de qué murió, que estuvo aproximadamente un mes enfermo "y quien lo asistió es curandero llamado médico del agua fría, y que se llama Manuel". ${ }^{8}$ Aquí no podemos aseverar si el padre del niño dijo curandero o fue el término agregado por el funcionario judicial. Sin embargo, del empleo del apelativo "médico del agua fría" puede inferirse que,, para la población esto era un tipo de práctica médica reconocida y avalada. Ahora bien, cuando se le pidió que describiera el tratamiento dispensado a su hijo pueden apreciarse la combinación de elementos de la religiosidad para la curación del pequeño. Games le había suministrado un líquido "del color del agua" con el que le hacía cinco curas diarias. El mecanismo consistía en que el niño tomara tres tragos junto a la recitación de una oración que el mismo Games les había enseñado: "En el nombre de Dios nuestro señor Todopoderoso y de los Cielos". Se infiere que la curación del enfermo vendría por intermediación divina y que el agua posiblemente barriera con la enfermedad. ${ }^{9}$

Dos similitudes con el caso anterior. Primero, el empleo de agua para la sanación, segundo, una oración en la que se le encomendaba a Dios la restitución de la salud del

\footnotetext{
${ }^{5}$ AHDJSPBS/JC. Exp. 172/12/1895 fs. 2-3.

${ }^{6}$ AHDJSPBS/JC. Exp. 233/10/1901 f.1.

${ }^{7}$ AHDJSPBS/JC. Exp. 233/10/1901 f. 1.

${ }^{8}$ AHDJSPBS/JC. Exp. 233/10/1901 f. 2.

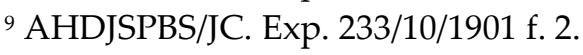


enfermo. El agua purificaba mediante la intervención de Dios. La presencia de cuestiones religiosas al analizar el curanderismo no es sorpresiva, por el contrario, como vimos en el caso anterior, la religiosidad era, en algunas prácticas, un factor determinante para la curación del enfermo. ${ }^{10} \mathrm{El}$ cargo por ejercicio ilegal de la medicina fue negado por el comerciante de 40 años Manuel Games, quien se defendió diferenciando el ejercicio ilegal de la medicina del curanderismo:

...no ejerce la medicina pero que ha asistido como a cien personas sometidas al tratamiento empleado al curanderismo y que es el siguiente: Suministra al paciente agua natural completamente pura y les ensaña á recitar una oración explicándoles [sic] el cumplimiento de las palabras que al tomar el remedio (...) siendo las siguientes "En el nombre de Dios, nuestro Señor Todopoderoso y de los Cielos". ${ }^{11}$

Aquí encontramos una contradicción de conceptos que hasta el momento no se nos había presentado. Usualmente en todas las fuentes que hemos analizado el curanderismo era asociado al ejercicio ilegal de la medicina. Sin embargo, de acuerdo a la declaración de Games, no eran lo mismo. Entendemos que en la cosmogonía del acusado ejercer la medicina no tenía que ver con dar agua pura y rezar. Esta sería una práctica de la medicina popular que él no asociaba directamente a la medicina académica. Además, al no autoproclamarse médico, en su imaginario negaba las acusaciones, pues él no era médico, sino una persona que curaba mediante curanderismo, lo cual sería la aplicación de la religiosidad y elementos naturales, en este caso del agua. Una diferencia con el caso de Jofre es que Games es un comerciante de la zona, es decir, que tenía arraigo y que probablemente su accionar estuviese ligado a completar sus ingresos (en el caso de que cobrase por sus servicios) o simplemente porque en verdad creía poseer cualidades excepcionales para la curación de ciertos males.

Volvemos al expediente. Games negó haber atendido en particular a este enfermo, pues cuando concurrió a verlo por pedido del padre ya había fallecido. Al indagar sobre la botella que consumió el niño, dijo que pudo haberle dado a Díaz una botella para sus otros hijos, que trató con anterioridad, pero no a este niño. Acerca de su función como curandero explicaba que asistía a los que estaban en mendicidad y "que tiene un don" para ello que ya ha explicado. Se vuelve en este expediente nuevamente al asistencialismo desde una persona que carecía de formación, pero que estaba convencido de poseer un don que debía poner al servicio de quienes lo necesitasen.

Finalmente, ratificó que él no ejercía la medicina "que ha curado a más de doscientas personas á quienes sólo les ha dado agua pura y haciéndoles rezar la oración ya dicha". ${ }^{12}$ Cuando le preguntaron si cobraba por sus servicios dijo: "que no cobra absolutamente nada porque pertenece á una sociedad de comunidad y fraternidad denominada

\footnotetext{
${ }^{10}$ AHDJSPBS/JC. Exp. 233/10/1901 f. 2.

${ }^{11}$ AHDJSPBS/JC. Exp. 233/10/1901 f. 3.

${ }^{12}$ AHDJSPBS/JC. Exp. 233/10/1901 fs. 7-8.
} 
'Pancho Sierra'."13 Esta pregunta en la mayoría de los expedientes es clave pues ello ayudaba o no a una condena. En relación a esto no tenemos mayores precisiones de la fraternidad "Pancho Sierra", pero estimamos que fueron un grupo de seguidores del curandero de Salto y Rojas, quienes adoptaron sus técnicas de curar mediante agua y rezos. La figura de Sierra, como ha señalado Di Liscia (2002, p. 245), no sería controversial en el ámbito académico, sino que se la percibía como parte de una tradición de la "ciencia gaucha" que debía ser estudiada y cuyas técnicas iban a ser retomadas por el espiritismo y el hipnotismo (Vallejo, 2014, p. 24). Sierra no fue perseguido por su forma de curar gracias a sus conexiones políticas (Bubello, 2010, pp. 37, 61). Pero sus seguidores no fueron tan afortunados, pues sus formas de curar les trajeron consecuencias de variada índole. Games y Jofre fueron sujetos a un proceso penal y, aunque fueron absueltos, no todos los médicos del agua fría corrieron con la misma suerte.

Aparentemente en el poblado de Lobos a fines del siglo XIX uno de los seguidores de Pancho Sierra fue denunciado por varios médicos del Consejo de Higiene a la Justicia por desobedecer sus resoluciones y practicar la medicina sin titulación. A mediados de 1881, la policía entregó al Juez de Paz de Lobos, Don Blas Varela, una nota en la que se notificó que habían remitido al Consejo de Higiene Pública una queja por ejercicio ilegal de la medicina en esa localidad contra un sujeto de apellido Castro Sierra, el cual había sido reincidente y el juzgado no había hecho nada al respecto: "Por mas [sic]que el Consejo de Higiene vea en este auto de remisión un exceso de celo por cumplir las disposiciones de la lei [sic] que rige el ejercicio de las diversas ramas del arte de curar, no puede menos que deplorar que el interés por la salud pública."14

En este sentido, las autoridades del Consejo expresaban su deseo de que esta vez el Juez hiciera caso a lo señalado por el Juzgado y lo detuviera. Es así que el 29 de julio de 1881 comparecieron ante el Juez de Paz los Doctores en Medicina Don José Piñeiro y Don Vicente Castañeda, quienes habían interrogado a Sierra Castro acerca de los cargos de ejercicio ilegal de la medicina, junto a la fabricación y dispensa de medicamentos, aunque el acusado se había negado a responder preguntas. Por esto y basándose en la ley de ejercicio del arte de curar el Dr. Piñeiro estableció que el Sr. Castro "fuese constituido en prisión" 15 siempre que siguiese ejerciendo el arte de curar o reincidiese.

En su descargo, el imputado acusó al Dr. Piñeiro, pues, aseveraba que "no creo sea la de un caballero y yo cumpliendo con la misión que llevo como homeopatico [sic] estoy en mi deber de poner á salvo mi honor ofendido por dos hombres que dicen ser Doctores" ${ }^{16}$ En principio, Sierra Castro se denominó como homeopático, que era una disciplina en retroceso en esos años debido a polémicas suscitadas entre sus defensores y detractores (González Korzeniewski, 2010, p. 39). Esta práctica implicaba la acción

\footnotetext{
${ }^{13}$ AHDJSPBS/JC. Exp. 233/10/1901 f. 8.

14 Archivo Histórico Provincial Ricardo Levene/Departamento Judicial de la Capital/Justicia Criminal (en adelante AHPRL/DJC/JC) Exp. 40-2/369/7/1881, f. 1.

${ }^{15}$ AHPRL/DJC/JC. Exp. 40-2/369/7/1881, f. 4.

${ }^{16}$ AHPRL/DJC/JC. Exp. 40-2/369/7/1881, f. 4.
}

Anuario de la Escuela de Historia Virtual - Año 11 - N 17 - 2020: pp. 36-56. ISSN: 1853-7049 
curativa de una droga que podía producir en el hombre sano una enfermedad, pero, al enfermo, podía llegar a curarlo (Weber, 1999; Cerrillo Vidal, 2008; De Almeida, 2018, p. 32). El acusado aparentemente se hallaba ofendido por las acusaciones, por lo que basó su defensa en la doctrina cristiana que lo impulsaba a ayudar a los enfermos y a no dejarlos caer en la muerte si le era posible evitarlo: “espero del Señor Juez cumpla su deber y no cometa ningún acto que permita que mi cuerpo caiga á la tierra despedasado [sic] á la tierra por cumplir con lo que Dios ordena dar de comer al ambriento [sic], vestir al desnudo y amparar al desgraciado enfermos que acuden a esta humilde casa". ${ }^{17}$

Concluía, finalmente, que era su misión obrar en función del bienestar de la humanidad por designio de Dios, y que lo único que suministraba era agua: "Espera bien yo haga bien y cumplir á Dios en primera hora mis puertas, se habrían [sic] y dan el remedio natural no son drogas 'agua' y 'agua' y 'agua'”. ${ }^{18} \mathrm{El}$ empleo del agua, la idea de realizar una buena obra para con los demás y la aparición de la homeopatía como práctica coinciden con una forma de curación híbrida en la que no solo la fe o la oración curaban a las personas. El argumento defensivo era simple: si se daba agua no era una droga, por lo que no se violaba ninguna ley, y lo que en verdad existía era una persecución de parte de otros médicos al accionar de una persona que solo buscaba el bienestar de la población.

A pesar de sus dichos, esta persona ya había sido notificada que no debía continuar con sus actividades. Un telegrama del juez de paz de Saladillo, J. Sarmiento, al de Lobos, anexado al expediente daba cuenta que Maximiliano Sierra ó Castro había sido apercibido por ese Juzgado por ejercer indebidamente la profesión de médico y fue remitido a Chivilcoy. Ante esto, el Consejo de Higiene Pública (CHP) hizo hincapié nuevamente en que le dejaron claro cuáles debían ser sus atribuciones al respecto, que labrara lo más rápido posible el sumario para que este $\mathrm{CHP}$ pudiera tomar medidas. Se llamó a los testigos y comenzó la larga reconstrucción de los hechos. Ante ellos compareció Eduardo Martínez, quien dijo conocer a Castro y que "se ocupa[ba] en desempeñar las funciones de médico pero que no le conoce profesión arte, ni oficio alguno, que le consta de un modo positivo que en su domicilio admite todos los días enfermos que se van a hacer asistir".${ }^{19}$ No queda claro entonces cómo lo veía Martínez si era considerado médico, o bien sabían que era un curandero y para ellos era lo mismo. No hubo en su testimonio mayores precisiones sobre el mecanismo empleado, pero sí detalló cómo Sierra Castro se hallaba enojado con el Dr. Piñeiro y los supuestos motivos por los que acudió a Lobos. Relató que se encontró con Castro en el tren, quien le manifestó que había sido convocado a la ciudad por sus maravillosas curas en Lobos, y agregó "que había dado el habla a un mudo que el Dr. Piñeiro no había sabido curar" 20. A su vez, afirmaba que los "médicos de esta localidad no conocían el cuerpo humano y

\footnotetext{
${ }^{17}$ AHPRL/DJC/JC. Exp. 40-2/369/7/1881, f. 5.

${ }^{18}$ AHPRL/DJC/JC. Exp. 40-2/369/7/1881, f. 5.

${ }^{19}$ AHPRL/DJC/JC. Exp. 40-2/369/7/1881, f. 8.

${ }^{20}$ AHPRL/DJC/JC. Exp. 40-2/369/7/1881, f. 8.
} 
que el volvería a Lobos con el fin de continuar el arte de curar y que ni el Juez de Paz ni los médicos de la localidad se lo impedían". ${ }^{21}$ Este curandero, es un itinerante de acuerdo a lo recabado en el expediente, venía huyendo de acusaciones similares en otras localidades del interior de la provincia, cambiando hábilmente de jurisdicción. Esta modalidad es similar a la explicitada por Irina Podgorny (2015) sobre los charlatanes de inicios del siglo XIX en Argentina. Acerca de la imputación sobre expendio de medicamentos, el declarante señaló que había visto varias personas salir de allí con frascos de drogas o medicamentos. En la foja 10 consta que diariamente atendía más o menos entre 20-30 personas. Asimismo, manifestó que había oído quejas del médico titulado por el mal trato, abusos y palabras inmorales "á [sic] los infelices que han sido engañados". ${ }^{22}$ Brindó los nombres de Gaspar Borra, Severo Rodríguez, Tomás Villafañe, Cruz Thompson, quienes habían concurrido a que les hicieran las "supuestas curas". ${ }^{23}$

La declaración de Gaspar Borra corroboró en parte la del testigo anterior, pues sabía que ejercía el arte de curar. Fue a verlo a causa de un adormecimiento en la pierna producto de un grano, pero Castro no logró curarlo correctamente. Seguidamente afirmó que en la casa del acusado vio curar gente y también que ignoraba si expedía medicamentos. Otro de los mencionados, Avelino Suarez relató algo similar. Cuando fue a curarse de una serie de dolencias creyendo que era médico, observó cómo atendía a varias personas aunque no podía decir si expedía medicamentos. Otro testigo, Ignacio Merrofalvis, dijo que Castro era conocido como "médico del agua fría asiste y ejerce el arte de curar actualmente en esta localidad". ${ }^{24}$ Relató que una hermana del declarante, Andrea Merrafaldis, fue a verlo por un dolor en la espalda y que le dijo:

el Médico del Agua Fría le había dado un remedio y una copa de un Líquido amarillo que le hizo tomar en la casa el médico y que á consecuencia de esto estaba que no sabía lo que tenía en la cabeza, que á los dos días de esto ha sido necesario llevarla al asilo de dementes porque su referida hermana había perdido la razón y se encontraba en completo estado de demencia, que esto ha sucedido hace ochos días más o menos. ${ }^{25}$

Este caso respaldaría las acusaciones por parte de los médicos hacia la medicina popular como una de las causantes de las enfermedades de la población. Según el testimonio del hermano, una mujer había recibido un tratamiento $\mathrm{y}$, en efecto, sus facultades mentales se vieron alteradas, aunque tengan que considerarse como especulaciones, dado que carecemos de mayores precisiones al respecto. En el caso de José Mendoza, el empleador de Castro, dijo que sabía y le constaba que el acusado ejercía el arte de curar pues era su cocinero, y que también le expedía medicamentos y drogas: “todos los enfermos que iban a hacerse asistir con este Señor salían con unas de botellas

\footnotetext{
${ }^{21}$ AHPRL/DJC/JC .Exp. 40-2/369/7/1881, f. 8.

22 AHPRL/DJC/JC. Exp. 40-2/369/7/1881, f. 10.

${ }^{23}$ AHPRL/DJC/JC. Exp. 40-2/369/7/1881, f. 8.

${ }^{24}$ AHPRL/DJC/JC. Exp. 40-2/369/7/1881, f. 15.

${ }^{25}$ AHPRL/DJC/JC. Exp. 40-2/369/7/1881, f. 15.
} 
con líquidos y otros con cajas de verduras, que el declarante también se había hecho asistir con el expresado Castro el cual le había dado una toma que ignora que sería". ${ }^{26}$

Recalcó que en la casa también se elaboraban medicamentos y que el declarante había hecho "cocimientos de zarzaparrilla y el Señor Castro freiasinto-senisal, o grasas que no sabe precisar el exponente y después lo hacía conducir á su pieza donde elaboraba los medicamentos" ${ }^{27}$ Finalmente, teniendo en cuenta los antecedentes y las testimoniales se lo condenó con 5.000 pesos de multa.

Por último, el caso del yugoeslavo Elías Kolak, quien en palabras de su nuera: "se dedica al arte de curar empleando métodos naturalistas, y solo administra a sus pacientes aguas de preparado vegetal y una pomada especial cuya composición desconoce, entendiendo que ello constituye un secreto de su suegro" ${ }^{28} \mathrm{~A}$ diferencia de los casos del siglo XIX, a Kolak lo apresan luego de una investigación en la que policías se hicieron pasar por pacientes para hallarlo in fraganti. En su declaración del 16 de enero, Elías Kolak dijo ser hijo de José Kolak y Estoya, nacido en el pueblo de Susac, provincia de Lica, Yugoeslavia, el 2 de agosto de 1842, viudo, analfabeto, agricultor y avicultor. Sus palabras, mediadas claramente por el funcionario judicial, resultan interesantes a los ojos del siglo XXI pues deja entrever escuetamente el origen de su profesión como una herencia:

el declarante desciende de una generación de personas que se dedican al arte de curar y en su país de origen yá practicaba tales actividades.-Que en esta ciudad se radicó hace diecisiete años y desde entonces ha venido ejerciendo el curanderismo, pero sin animarlo por finalidad exclusiva de lucro, pues como ha dicho sus mayores ya realizaban curas; además el que depone tiene una fracción de tierras que cultiva y de ello vive como también de la cría de aves, alternando estos trabajos con el de curar personas. Que no fija precios a ninguna persona y sigue en esto caso una tradición de sus antepasados, limitándose a aceptar pequeñas dádivas de sus pacientes consistentes en ínfimas cantidades de dinero, que oscilan en veinte centavos, treinta o cuarenta, excediendo rara vez de un peso moneda nacional. Que no administra drogas, sólo da a sus pacientes agua de preparado vegetal y de virtudes curativas innegables, pues es sabido que toda hierba tiene una propiedad benéfica para el organismo, como lo han demostrado los médicos naturalistas que hoy en día se especializan en esta rama de la medicina... ${ }^{29}$

El inventario de los objetos secuestrados en el allanamiento a su casa en la ciudad de Mar del Plata en la década del '40 nos presenta una imagen sobre cómo el espacio y el ritual podían ser necesarios para llevar a cabo la curación: "el nombrado tenía instalado un altar que le fue secuestrado, dos crucifijos, dos cuadros con imágenes religiosas, varias cajas conteniendo velas, candeleros, plumeros y otros objetos incautados". ${ }^{30}$ Todo apuntaba a una conjunción entre elementos religiosos y el suministro de pócimas y

${ }^{26}$ AHPRL/DJC/JC. Exp. 40-2/369/7/1881, f. 23.

${ }^{27}$ AHPRL/DJC/JC. Exp. 40-2/369/7/1881, f. 23.

${ }^{28}$ AHDJSPBS/JC. Exp. 6/9/1941 f. 7.

${ }^{29}$ AHDJSPBS/JC. Exp. 6/9/1941 f. 9.

${ }^{30}$ Telegrama al principio del expediente página sin numerar. AHDJSPBS/JC. Exp. 6/9/1941 f. 2. 
preparados que actuarían en conjunto. En este sentido, las autoridades se tomaron el trabajo de describir la posición de las cosas dando a entender que sus curaciones guardaban una estrecha relación con la religiosidad popular:

en una habitación de la finca, sobre el ángulo sur de la misma, existe un altar, formado sobre una mesa de madera, la que se halla cubierta por un mantel con puntillas, donde existe un crucifijo de estaño de regular tamaño, uno más pequeño del mismo metal, dos cuadros con imágenes religiosas, un libro del evangelio en idioma europeo, un candelabro, un escudo del Congreso Eucarístico realizado en la ciudad de Buenos Aires, varias cajas conteniendo velas de noche, cuatro carpetillas de hilo tejido, tres paquetes de velas, una corona de flores de papel, una cabeza de estaño representando a Jesús, tres floreritos de terracota, un florero de cristal color borravino, un mantelito de género color blanco con un sello religioso, una serena de papel adornado el primero de los crucifijos descriptos... ${ }^{31}$

El detalle del croquis de la habitación del imputado señala la importancia que tenía para los investigadores su matriz religiosa. El peso de la religiosidad es innegable en ciertas cuestiones. Uno de los tratamientos más habituales era el de la combinación de agua con rezos para poder sanar a los enfermos. Esta combinación nos permite vislumbrar el sincretismo que operaba en algunos de estos médicos populares, quienes empleaban uno de los símbolos más conocidos del cristianismo como es la purificación mediante el agua para sanar males corpóreos y de otra índole. Este tipo de creencias fueron consideradas desde mediados del siglo XIX como supersticiones y resabios de la incultura de los siglos precedentes. Sin embargo, esto no impidió que se los persiguiera y criminalizara por contradecir las leyes sobre ejercicio de la medicina. Su accionar era denunciado y menospreciado por los médicos, así como también por ciertos personajes de relevancia social y política en los poblados.

\section{A modo de conclusión}

Los estudios sobre el proceso de medicalización en la Argentina han tendido a centrarse en el discurso médico y literario de la época sin tomar en demasiada consideración los aspectos que la documentación judicial puede acercarnos. En este artículo intentamos, a través de una serie de casos, comprender cómo el componente cultural en ciertas oportunidades era imprescindible al momento de entender la medicina popular y sus adeptos.

Los curanderos que analizamos lejos se encuentran de los eruditos que, como Mauro Vallejo ha trabajado $(2018 ; 2019)$, aparecieron en ciertos momentos en la ciudad de Buenos Aires. Aquí presentamos sujetos cuyas prácticas y formas de pensar concordaban con la población que atendían. En el interior de la provincia, por más de sesenta años, y podemos aseverar que aún ocurre, el componente religioso ligado a la fe resultó indispensable para entender ciertas enfermedades, cuyos orígenes y curaciones

\footnotetext{
${ }^{31}$ AHDJSPBS/JC. Exp. 6/9/1941 f. 2.
} 
dependían casi exclusivamente de lo divino y de la existencia de personajes como los curanderos.

Si bien las menciones a la religión no son infrecuentes, tampoco son tan habituales en los casos judiciales si no se contemplan cuestiones relacionadas a la brujería y al esoterismo. Esto no quiere decir que no existiese un componente religioso en varias prácticas desarrolladas por distintos curanderos, sino que, como trabajamos en la justicia del crimen, los casos en los que los resultados eran la muerte o heridas graves no fueron documentados en su totalidad.

En este trabajo pudimos apreciar cómo un sector la población percibía a las enfermedades y sus consecuentes curas con una lógica divina. El empleo de fórmulas religiosas para la curación, o pensar que ciertas personas poseían un don para acabar con el padecimiento, nos remite a una fuerte impronta cultural y religiosa proveniente de los tiempos coloniales. Entendemos que esto debe ser profundizado y explorado para otras sociedades y espacios temporales. Esto podría hacerse probablemente empleando documentación de carácter folclórico que nos permita sumergirnos en la relevancia de lo cultural al tratar enfermedades y curaciones.

El empleo de la religión o, en nuestro caso en particular, de la religiosidad, apunta a una cuestión distinta de la medicina empírica o sus prácticas. Si bien a lo largo de los casos hemos visto cómo los rezos se conjugaban con friegas o tisanas, la idea central de quienes llevaban a cabo estas prácticas era que una deidad sería quien obraría la cura. Es así que el concepto de enfermedad y su consecuente curación tenían como origen y culminación el obrar divino. Como pudimos observar, esto no se modificó conforme avanzó el siglo XX. Al contrario, algunos casos llegaron a la prensa nacional y tuvieron amplia repercusión (Bubello, 2010, pp. 169 y sig.). Nuestros ejemplos y los de otros investigadores nos permiten señalar que lejos de desaparecer el curanderismo, en su faceta empírica o religiosa, fue un fenómeno de larga duración.

\section{Referencias bibliográficas:}

Allevi, J. I., Carbonetti, A. C. A. y Sedrán, P. M. (2018). Médicos, administradores y curanderos. Tensiones y conflictos al interior del arte de curar diplomado en la provincia de Santa Fe, Argentina (1861-1902). Anuario de Estudios Americanos, vol. 75 (1), 295-322.

Arteaga, F. y Funes, M. (2008). Sanadores tradicionales en contextos interculturales del Área Metropolitana de Buenos Aires (Argentina). Trabajo presentado en la $26^{\mathbf{a}}$ Reunión Brasilera de Antropología. Porto Seguro, Brasil.

Bianchetti, M. C. (1982). Antropología del área de la Puna. Documenta Laboris, Programa de Investigaciones sobre epidemiología Psiquiátrica. CONICET, 2.

Biernat, C., Cerdá, J. M. y Ramacciotti, K. I. (2015). La salud pública y la enfermería en la Argentina. Bernal: UNQ. 
Bjerg, M. M. (2004). El mundo de Dorothea: la vida en un pueblo de la frontera de Buenos Aires en el siglo XIX. Buenos Aires: Imago Mundi.

Bubello, J. P. (2007). Magia, milenarismo y represión judicial en una sociedad de frontera del norte patagónico: el juicio a Gerónimo Solané (1871-1872). Revista de Historia, vol. 11, 73-93.

Carbonetti, A. (2009). Prácticas empíricas y medicina académica a mediados del siglo XIX. Un análisis desde una perspectiva cuantitativa. Ponencia presentada en Jornadas Interinstitucionales sobre historia de la salud y la enfermedad en América Latina. Benemérita Universidad de Puebla, Instituto de Ciencias Sociales y Humanidades Alfonso Pérez Pliego, Puebla.

Caro Baroja, J. (1995). Las formas complexas de la vida religiosa. Barcelona: Círculo de Lectores.

Cerrrillo Vidal, J. A. (2008). ¿Medicina alternativa? Una aproximación a las metáforas de salud y enfermedad en los discursos médicos oficial y homeopático. Intersticios, vol. 2 (1), 115-130.

Conforte, A. J. y Vallejo, M. S. (2016). Hipnosis y magnetismo en la Revista Magnetológica (1897-1903). Anuario de Investigaciones, vol. 23 (2), 259-268.

Da Orden, M. L. (2005). Inmigración española, familia y movilidad social en la Argentina moderna: una mirada desde Mar del Plata (1890-1930). Buenos Aires: Biblos.

Dahhur, A. (2015). Los maestros entre la condena y la aceptación de la medicina tradicional en la provincia de Buenos Aires. La cultura popular y la cultura docta en la Encuesta Nacional de Folclore de 1921. Sociedad y Discurso, vol. 28, 94-114.

Dahhur, A. (2019). La medicina popular bajo la lupa. Concepciones, discursos y representaciones de un arte de curar en la provincia de Buenos Aires (1870-1944). Tesis de doctorado. Buenos Aires, Facultad de Ciencias Sociales, Pontificia Universidad Católica Santa María de los Buenos Aires.

De Almeida, D. H. (2018). Nós aquí cura com benzedura e raíz de pau. Experiências de curas a partir da cultura popular brasileira e portuguesa (século XX). Tesis de doctorado. Río de Janeiro, Casa de Oswaldo Cruz-Fiocruz.

Di Liscia, M. S. (2002). Saberes, terapias y prácticas médicas en Argentina (1750-1910). Madrid: CSIC-CSIC Press.

Di Stefano, R. (2011). Por una historia de la secularización y de la laicidad en la Argentina. Quinto Sol, vol. 15 (1), 1-31.

Farberman, J. (2005). Las Salamancas de Lorenza, magia hechicería y curanderismo en el Tucumán colonial. Buenos Aires: Siglo XXI editores.

Farberman, J. (2010). Magia, brujería y cultura popular. De la Colonia al siglo XX. Buenos Aires: Sudamericana.

Fleitas, M. (2007). ¡Queremos a Mano Santa!: actores y significados de una revuelta popular acontecida en 1929 en San Salvador de Jujuy. Salud colectiva, vol. 3 (3), 301313. 
González Korzeniewski, M. A. (2010). El mito fundacional de la homeopatía argentina. La Revista Homeopatía, Buenos Aires (1933-1940). Asclepio, vol. 62 (1), 35-60.

González Leandri, R. (1999). Curar, persuadir, gobernar: la construcción histórica de la profesión médica en Buenos Aires, 1852-1886. Madrid: CSIC-CSIC Press.

Granada, D. (1947) [1896]. Reseña histórico-descriptiva de antiguos y modernas supersticiones del Río de la Plata. Buenos Aires: Ed. Kraft.

Ingenieros, J. (2003 [1903]). La simulación de la locura. https://www.biblioteca.org.ar/libros/8815.pdf, Consultado el 7 de mayo de 2018.

Irianni, M. (2000). Inmigrantes vascos tras el mostrador ¿Audacia o lógica en la pampa argentina durante el siglo XIX? Studi Emigrazione, vol. 138, 431-451.

Levene, R. (1940). Historia de la provincia de Buenos Aires: y formación de sus pueblos. La Plata: Talleres de Impresiones Oficiales.

Macc Cann, W. (1939) [1847]. Viaje a caballo por las provincias argentinas. Buenos Aires: Imprenta Ferrari.

Mailhe, A. (2017). Creencias y supersticiones en conflicto: visiones de la religiosidad popular en la Argentina de entresiglos. Orbis Tertius, vol. 22 (26), e051-e051.

Mallimaci, F. (Comp.) (2008). Modernidad, religión y memoria. Buenos Aires: Ediciones Colihue.

Martín, E. (2007). Aportes al concepto de "religiosidad popular" una revisión de la bibliografía argentina. En M. J. Carozzi y C. Ceriani Cernadas (Coords.), Ciencias Sociales y Religión en América Latina (pp. 61-79). Buenos Aires: Editorial Biblos.

Márquez, J. y Estrada, V. (2018). Culebrero, tegua, farmaceuta y dentista. El Indio Rondín y la profesionalización médica en Colombia, 1912-1934. Anuario Colombiano de Historia Social y de la Cultura, vol. 45 (1), 79-104.

Míguez, E. (2009). Historia económica de la Argentina. De la Conquista a la crisis de 1930. Buenos Aires: Sudamericana.

Míguez, E. (2013). La provincia de Buenos Aires entre 1980 y 1943. En J. M. Palacios (Comp.), Historia de la provincia de Buenos Aires: de la federalización de Buenos Aires al advenimiento del peronismo (1880-1943) (pp. 15-47). Buenos Aires: Edhasa.

Nario, H. (1976). Tata Dios: El Mesías de la última montonera. Buenos Aires: Plus Ultra.

Palmer, S. (2003). From Popular Medicine to Medical Populism: Doctors, Healers, and Public Power in Costa Rica, 1800-1940. Durham: Duke University Press.

Podgorny, I. (2015). Charlatanería y cultura científica en el siglo XIX. Madrid: Catarata.

Ramos Mejía, J. (1904). Los simuladores del Talento. Buenos Aires: Félix Lojaune Editores.

Ratier, H. (1972). La medicina popular. La historia popular. Buenos Aires: CEAL.

Rivero, M. D. y Carbonetti, A. (2019). ¿Explotadores de la salud? Un estudio sobre miradas médicas desde Córdoba, Argentina, en torno a saberes empíricos vinculados a las prácticas de curar (1930-1940). Folia Histórica del Nordeste, (34), 65-90.

Rivero, M. D., Carbonetti, A. y Rodríguez, M. L. (2017). Diplomat/certified knowledge alternatives in the public scene: an approximation to the quackery from the written 
press of the cities of Córdoba and Buenos Aires, Argentina in the 1920s. Historia $y$ Sociedad, (33), 19-43.

Rivero, D. y Vanadía, L. (2018). En los márgenes de la biomedicina: perspectivas en torno a la práctica ilegal de la medicina en Córdoba y Buenos Aires, 1920-1930. Trashumante. Revista Americana de Historia Social, (11), 98-121.

Santamaría, Daniel. (1991). La cuestión de la religiosidad popular en la Argentina. En M. E Chapp y otros, Religiosidad popular en la Argentina (pp. 16-33). Buenos Aires: CEAL. Santos, J. J. (2012). El tata Dios: Milenarismo y xenofobia en las pampas. Buenos Aires: Sudamericana.

Scarpa, G. F. (2004). El síndrome cálido-fresco en la medicina popular criolla del Chaco argentino. Disparidades. Revista de Antropología, vol. 59 (2), 5-29.

Sowell, D. (2002). Andanzas de un curandero en Colombia: Miguel Perdomo Neira. En D. Armus (Ed.), Entre médicos y curanderos: cultura, historia y enfermedad en la América Latina moderna (pp. 71-103). Buenos Aires: Grupo Editorial Norma.

Vallejo, M. S. (2014). Buenos Aires mesmérica. Hipnosis y magnetismo en la cultura y la ciencia de la capital argentina (1870-1900). Iberoamericana, vol. 56, 7-26.

Vallejo, M. S. (2018). El Instituto Psicológico Argentino (1892). Teosofía, hipnosis y charlatanería en los orígenes de una iniciativa olvidada. Asclepio, vol. 70 (1), 217-230.

Viotti, N. (2014). La violencia invisible. Hechicería, agresión y persona en los Andes. Cadernos de Campo (São Paulo, 1991), vol. 23 (23), 141-157.

Weber, B. T. (1999). As artes de curar: medicina, religiäo, magia e positivismo na República RioGrandense-1889-1928. Santa Maria: Ed. Da UFSM; Bauru: EDUSC-Editora da Universidade do Sagrado Coração.

Para citar este artículo:

Dahhur, Astrid (2020). Religión, medicina popular y curanderos en la provincia de Buenos Aires (Argentina, 1880-1941). Anuario de la Escuela de Historia Virtual, 17, 36-56. 